\title{
Apigenin overcomes drug resistance by blocking the signal transducer and activator of transcription 3 signaling in breast cancer cells
}

\author{
HYE-SOOK SEO ${ }^{1}$, JIN MO KU ${ }^{2}$, HYEONG SIM CHOI ${ }^{1}$, JONG-KYU WOO ${ }^{3}$, BYUNG HOON LEE ${ }^{2}$, \\ DOH SUN KIM ${ }^{2}$, HYUN JONG SONG ${ }^{4}$, BO-HYOUNG JANG ${ }^{1}$, YONG CHEOL SHIN ${ }^{1}$ and SEONG-GYU KO ${ }^{1}$ \\ ${ }^{1}$ Laboratory of Clinical Biology and Pharmacogenomics and Center for Clinical Research and Genomics, \\ College of Korean Medicine, Kyung Hee University; ${ }^{2}$ Department of Science in Korean Medicine, \\ Graduate School, Kyung Hee University, Dongdaemun-gu, Seoul 02447; ${ }^{3}$ College of Veterinary Medicine, \\ Seoul National University, Gwanak-gu, Seoul 08826; ${ }^{4}$ Department of Applied Korean Medicine, \\ Graduate School, Kyung Hee University, Dongdaemun-gu, Seoul 02447, Republic of Korea
}

Received January 13, 2017; Accepted May 15, 2017

DOI: $10.3892 /$ or.2017.5752

\begin{abstract}
Drug resistance in chemotherapy is a serious obstacle for the successful treatment of cancer. Drug resistance is caused by various factors, including the overexpression of P-glycoprotein (P-gp, MDR1). The development of new, useful compounds that overcome drug resistance is urgent. Apigenin, a dietary flavonoid, has been reported as an anticancer drug in vivo and in vitro. In the present study, we investigated whether apigenin is able to reverse drug resistance using adriamycin-resistant breast cancer cells (MCF-7/ADR). In our experiments, apigenin significantly decreased cell growth and colony formation in MCF-7/ADR cells and parental MCF-7 cells. This growth inhibition was related to the accumulation of cells in the sub- $\mathrm{G}_{0} / \mathrm{G}_{1}$ apoptotic population and an increase in the number of apoptotic cells. Apigenin reduced the mRNA expression of multidrug resistance 1 (MDR1) and multidrug resistance-associated proteins (MRPs) in MCF-7/ADR cells. Apigenin also downregulated the expression of P-gp. Apigenin reversed drug efflux from MCF-7/ADR cells, resulting in rhodamine 123 (Rho123) accumulation. Inhibition of drug resistance by apigenin is related to the suppression of the signal transducer and activator of transcription 3 (STAT3) signaling pathway. Apigenin decreased STAT3 activation (p-STAT3) and its nuclear translocation and inhibited the secretion of VEGF and MMP-9, which are STAT3 target genes. A STAT3
\end{abstract}

Correspondence to: Dr Seong-Gyu Ko, Laboratory of Clinical Biology and Pharmacogenomics and Center for Clinical Research and Genomics, College of Korean Medicine, Kyung Hee University, 26 Kyungheedae-ro, Dongdaemun-gu, Seoul 02447, Republic of Korea

E-mail: epiko@khu.ac.kr

Key words: breast cancer, apigenin, drug resistance, multidrug resistance 1, signal transducer and activator of transcription 3 inhibitor, JAK inhibitor I and an HIF-1 $\alpha$ inhibitor decreased cell growth in MCF-7 and MCF-7/ADR cells. Taken together, these results demonstrate that apigenin can overcome drug resistance.

\section{Introduction}

Chemotherapy is one of the major modalities of cancer treatment; however, the effect of chemotherapy is often diminished by drug resistance (1). The occurrence of chemoresistance is a serious problem during the treatment of local and disseminated disease (2). Based on tumor response to the initial therapy, cancer resistance can be seperated into two categories, intrinsic or acquired $(1,3)$. Intrinsic drug resistance concerns patients who express pre-existing, resistance-mediating factors before receiving chemotherapy. Acquired drug resistance is related to patients who were initially sensitive to the chemotherapy but who developed resistance during treatment $(1,3)$. Numerous advanced techniques have increased our ability to identify novel genes and signaling pathways that are related to tumor responsiveness to a particular drug treatment (1). Various mechanisms of overcoming drug resistance have been developed to treat cancer (4).

Drug resistance is caused by a variety of factors, such as cancer stem cells, drug efflux, drug inactivation, alterations in drug targets, DNA damage repair, and deregulated apoptosis (1). Among these factors, drug efflux-mediated resistance due to overexpression of $\mathrm{ABC}$ transporters is the most frequent occurrence (4). $\mathrm{ABC}$ transport molecules, which are expressed on the cellular membrane and on the membranes of small vesicles, have important physiologic functions and affect the transport of chemotherapeutic reagents in humans $(4,5)$. Currently, there are 48 transporters in the ABC family, and 13 of the $\mathrm{ABC}$ transporters are related to tumor drug resistance, including P-glycoprotein (P-gp, MDR1/ABCB1), multidrug resistance proteins (MRPs/ABCCs) and breast cancer resistance protein (BCRP/ABCG2) (4,5). P-gp (MDR1) normally protects several organs from toxic compounds, inhibiting them 
from entering the cytosol and discharging them to the cell exterior (5). However, in patients with tumors, P-gp (MDR1) ejects chemotherapeutic agents out of the cells, decreasing their efficacy. P-gp (MDR1) is overexpressed in cancer cells and is one of the main obstacles to successful chemotherapy treatments for cancer (5).

Apigenin (4',5,7-trihydroxyflavone) is a flavone found in various plants. Apigenin present in common fruits and vegetables, such as apples, grapes, cherries, celery, parsley, Chinese cabbage, bell peppers, wine and tea. Similar to most flavones, apigenin has anti-inflammatory (6), antioxidant (7), anti-telomerase (8) and antidepressant (9) properties. The most important characteristic of apigenin is its anticancer activity. Previous studies indicate that apigenin induces a decreased risk of certain cancers, particularly breast, digestive tract, skin, prostate, lung, and ovary cancers and certain hematological malignancies (10-15). In in vivo models, apigenin inhibited prostate cancer progression in a transgenic adenocarcinoma of the mouse prostate (TRAMP) model (16). Apigenin induced attenuation of tumor growth in U937 xenografts (17). Apigenin strongly inhibited tumor growth in nude mice (18). In in vitro models, apigenin inhibited cell growth and induced apoptosis in cancer cell lines including breast (19), lung (20), colon (21,22), prostate (23), leukemia (24), and pancreatic (25) cells. These reports propose that apigenin could be used as a chemopreventive and/or chemotherapeutic agent for cancer.

STAT3 is a transcription factor that modulates development and physiology, and it is abnormally expressed in pathological situations such as cancer (26). Upon ligand binding, STAT3 is activated, resulting in dimerization, translocation to the nucleus, binding to DNA response elements and the induction of transcription of genes implicated in cell survival and proliferation. Cancer cells expressing constitutively activated STAT3 are more resistant to apoptosis and chemotherapy (26).

In this study, we investigated whether apigenin overcomes drug resistance and the mechanism of action. For this purpose, we tested the effects of apigenin on proliferation and apoptosis of MCF-7 cells and adriamycin-resistant MCF-7/ADR cells. We analyzed whether apigenin recovers cells from adriamycin resistance, resulting in downregulation of $\mathrm{P}-\mathrm{gp}$ (MDR1) expression. We also investigated whether apigenin inhibits the STAT3 signaling pathway, leading to the suppression of breast cancer development and drug resistance. We report here that apigenin overcomes drug resistance, thus it may help in cancer treatment.

\section{Materials and methods}

Compounds. Apigenin (4',5,7-trihydroxyflavone), HIF-1 $\alpha$ (hypoxia-inducible factor 1- $\alpha$ ) inhibitor (EF-24), 7-aminoactinomycin D (7-AAD), rhodamine 123 and nicardipine were purchased from Sigma Chemical Co. (St. Louis, MO, USA). These compounds were dissolved in dimethyl sulfoxide (DMSO) or ethanol, and the final concentration of DMSO or ethanol in the controls and in each sample did not exceed $0.1 \%$. The STAT3 inhibitor (S3I-201) was purchased from Calbiochem (San Diego, CA, USA). JAK (Janus kinase) inhibitor I was obtained from Santa Cruz Biotechnology, Inc. (Santa Cruz, CA, USA). Annexin V, Alexa Fluor ${ }^{\circledR} 488$ Conjugate was purchased from Thermo Fisher Scientific Korea
(Seoul, Korea). An EZ-western chemiluminescent detection kit was obtained from Daeillab Service Co. (Seoul, Korea).

Cell culture. MCF-7 (ATCC, American Type Culture Collection, Manassas, VA, USA) and MCF-7/ADR (a gift from Professor Hwa Jeong Lee, Ewha Womans University, Seoul, Korea) cells were cultured in Dulbecco's modified Eagle's medium (DMEM) and RPMI-1640 medium, respectively, containing $50 \mathrm{U} / \mathrm{ml}$ penicillin, $50 \mathrm{mg} / \mathrm{ml}$ streptomycin and $10 \%$ fetal bovine serum (FBS; Welgene, Daegu, Korea) at $37^{\circ} \mathrm{C}$ in an atmosphere of $5 \% \mathrm{CO}_{2}$.

Antibodies. Primary antibodies directed against cleaved caspase-8, poly(ADP-ribose) polymerase (PARP) and P-gp (MDR1) were obtained from Cell Signaling Technology, Inc. (Danvers, MA, USA). Primary antibodies directed against STAT3 and phospho-STAT3 (Tyr705) were purchased from Upstate-Millipore (Billerica, MA, USA). The anti-tubulin antibody came from Sigma Chemical Co. Horseradish peroxidase (HRP)-conjugated secondary antibodies (mouse and rabbit) were obtained from Calbiochem, and anti-goat secondary antibody was from Jackson ImmunoResearch (West Grove, PA, USA).

MTT assay. MCF-7 and MCF-7/ADR cells were plated in 96-well culture plates at a density of $3 \times 10^{3}$ cells/well and incubated for $24 \mathrm{~h}$ at $37^{\circ} \mathrm{C}$. Then, they were treated with adriamycin $(0-20 \mu \mathrm{g} / \mathrm{ml})$, apigenin $(0-100 \mu \mathrm{M})$, STAT3 inhibitor (0-500 $\mu \mathrm{M})$, JAK inhibitor I $(0-10 \mu \mathrm{M})$, or HIF-1 $\alpha$ inhibitor $(0-100 \mu \mathrm{M})$ for 48 or $72 \mathrm{~h}$. After incubation, MTT reagents $(0.5 \mathrm{mg} / \mathrm{ml})$ were inserted to each well, and the plates were incubated in a humidified incubator at $37^{\circ} \mathrm{C}$ for $2 \mathrm{~h}$. At the end of the incubation period, the medium was removed, the resulting formazan was dissolved in DMSO, and the optical density was determined at $570 \mathrm{~nm}$ using an ELISA plate reader.

Clonogenic survival assay. For the colony formation assay, MCF-7 and MCF-7/ADR cells were plated in 6-well culture plates at a density of $5 \times 10^{2}$ cells/well. After $24 \mathrm{~h}$, the cells were treated with different concentrations of apigenin $(0-80 \mu \mathrm{M})$ or vehicle and maintained for 10 days at $37^{\circ} \mathrm{C}$. Medium was changed every 3 days. Finally, the plates were stained with hematoxylin, and colony numbers were counted.

Cell cycle analyses by flow cytometry. MCF-7 and MCF-7/ ADR cells treated with apigenin $(0-80 \mu \mathrm{M})$ were harvested with $0.25 \%$ trypsin and washed once with phosphate-buffered saline (PBS). After the cells were centrifuged, they were fixed in cold $95 \%$ ethanol with $0.5 \%$ Tween-20 and stored at $-20^{\circ} \mathrm{C}$ for at least $30 \mathrm{~min}$. The cells were incubated in $50 \mu \mathrm{g} / \mathrm{ml}$ of propidium iodide (PI) (including $1 \%$ sodium citrate and $50 \mu \mathrm{g} / \mathrm{ml}$ RNase A) at room temperature in the dark for $30 \mathrm{~min}$. The analysis of apoptotic cells was performed with a FACScan flow cytometer (Becton-Dickinson, Mountain View, CA, USA), and the data were analyzed using CellQuest software.

Annexin V/7AAD apoptosis assay. Apoptotic cell death was measured by an Annexin V-FITC and 7-AAD assay. Cells were stained with Annexin V-FITC and 7-AAD for $30 \mathrm{~min}$ 
Table I. Primer sequences.

\begin{tabular}{lcll}
\hline Type & Primer name & & \multicolumn{1}{c}{ Sequences } \\
\hline Human & MDR1 & Forward: & 5'-CCC ATC ATT GCAATA GCA GG-3' \\
Human & MRP1 & Reverse: & 5'-GTT CAA ACT TCT GCT CCT GA-3' \\
Human & & Forward: & 5'-GCC GAA GGA GAG ATC ATC-3' \\
& MRP3 & Reverse: & 5'-AAC CCG AAA ACA AAA CAG G-3' \\
Human & MRP5 & Forward: & 5'-GTG GGG ATC AGA CAG AGA T-3' \\
Human & & Reverse: & 5'-TAT CGG CAT CAC TGT AAA CA-3' \\
& BCRP & Forward: & 5'-CAG CCA GTC CTC ACA TCA-3' \\
Human & & Reverse: & 5'-GAA GCC CTC TTG TCT TTT TT-3' \\
& GAPDH & Forward: & 5'-TGA CGG TGA GAG AAAACT TAC-3' \\
& & Reverse: & 5'-TGC CAC TTT ATC CAG ACC T-3' \\
\hline
\end{tabular}

RT-PCR was performed by co-amplification of the genes with a reference gene by use of the cDNA template and corresponding gene-specific primer sets.

at room temperature in the dark. The apoptotic cell population was analyzed with a FACSCalibur ${ }^{\mathrm{TM}}$ flow cytometer by measuring the signal in the FL-1 and FL-3 channels.

Western blot analysis. Harvested cells were lysed in modified RIPA buffer containing $150 \mathrm{mM} \mathrm{NaCl}, 1 \% \mathrm{NP}-40$, $0.5 \%$ deoxycholate, $0.1 \%$ SDS, $50 \mathrm{mM}$ Tris ( $\mathrm{pH} 8.0), 1 \mathrm{mM}$ EDTA, $1 \mathrm{mM}$ phenylmethylsulfonyl fluoride (PMSF), $1 \mathrm{mM}$ $\mathrm{NaF}, 1 \mathrm{mM} \mathrm{Na}_{3} \mathrm{VO}_{4}$ and a protease inhibitor mixture]. The lysates were cleared by centrifugation at $13,000 \mathrm{rpm}$ for $15 \mathrm{~min}$ at $4^{\circ} \mathrm{C}$. The supernatants were collected and stored at $-70^{\circ} \mathrm{C}$ until use. The protein concentration was quantified using a Bio-Rad Bradford protein assay (Bio-Rad, Hercules, CA, USA). Total proteins ( $30 \mu \mathrm{g})$ were electrophoresed using 6-15\% reducing SDS-polyacrylamide gels and transferred to nitrocellulose membranes. After blocking with $0.1 \%$ Tween-20 in PBS (PBST) containing 1\% skim milk and 1\% BSA for $1 \mathrm{~h}$, the membranes were incubated overnight at $4^{\circ} \mathrm{C}$ with the indicated primary antibodies. After washing in 1X PBST for $15 \mathrm{~min}$ ( 3 times $x 5 \mathrm{~min}$ ), the membranes were incubated with diluted enzyme-linked secondary antibodies. After washing in $1 \mathrm{X}$ PBST for $1 \mathrm{~h}$ (4 times x $15 \mathrm{~min}$ ), the protein bands were detected using the EZ-western chemiluminescent detection kit and visualized by exposing the membranes to X-ray film.

Immunocytochemistry. MCF-7 and MCF-7/ADR cells ( $2 \times 10^{4}$ cells/well) were plated in 8 -well chamber slides, incubated overnight at $37^{\circ} \mathrm{C}$ and treated with apigenin $(80 \mu \mathrm{M})$ for $24 \mathrm{~h}$. The cells were fixed with $4 \%$ paraformaldehyde for $30 \mathrm{~min}$ and treated with $3 \%$ hydrogen peroxide $\left(\mathrm{H}_{2} \mathrm{O}_{2}\right)$ in methanol for $20 \mathrm{~min}$. The cells were washed with PBS, blocked with 5\% BSA in PBS for $1 \mathrm{~h}$ and incubated with an anti-STAT3 primary antibody (1:100 dilution) for $24 \mathrm{~h}$ at $4^{\circ} \mathrm{C}$. After the cells were rinsed with PBS, they were incubated with anti-rabbit biotin-conjugated secondary antibody for $1 \mathrm{~h}$ at room temperature. Finally, the cells were treated with Vectastain ABC reagent (Vector Laboratories, Inc.
Burlingame, CA, USA) for $30 \mathrm{~min}$ at $4^{\circ} \mathrm{C}$ and stained with diaminobenzidine tetra chloride (DAB) and hematoxylin. The cells were mounted with mounting medium and subsequently analyzed by microscopy.

RNA extraction and reverse transcription-polymerase chain reaction ( $R T-P C R)$. RNA was isolated from cells using easy-blue RNA extraction kit (iNtRON Biotech, Sungnam, Korea) according to the manufacturer's instructions. Isolated RNA content was measured using the NanoDrop ND-1000 spectrophotometer (NanoDrop Technologies Inc., Wilmington, DE, USA). Total cellular RNA ( $2 \mu \mathrm{g})$ from each sample was reverse transcribed using cDNA synthesis kit (Takara, Otsu, Shiga, Japan). PCR was conducted in a $20-\mu 1$ reaction mixture consisting of DNA template, $10 \mathrm{pM}$ of each gene-specific primer, 10X Taq buffer, $2.5 \mathrm{mM}$ dNTP mixture, and $1 \mathrm{U}$ of Taq DNA polymerase (Takara). PCR was performed using the specific primer and primer sequences are shown in Table I.

Measurement of VEGF and MMP-9 secreted from MCF-7 and $M C F-7 / A D R$ cells by ELISA. The levels of VEGF (vascular endothelial growth factor) and MMP-9 (matrix metalloproteinases-9) were determined by sandwich ELISA using the BD Pharmingen human ELISA set (Pharmingen, San Diego, CA, USA). Briefly, plates were coated with capture antibody in ELISA coating buffer (Sigma) and incubated overnight at $4^{\circ} \mathrm{C}$. Plates were washed with PBS-Tween-20 (0.05\%) and subsequently blocked $\left(10 \% \mathrm{FBS}\right.$ in PBS) for $1 \mathrm{~h}$ at $20^{\circ} \mathrm{C}$. Serial dilutions of standard antigen or sample in dilution buffer (10\% FBS in PBS) were added to the plates and plates were incubated for $2 \mathrm{~h}$ at $20^{\circ} \mathrm{C}$. After washing, biotin-conjugated anti-mouse IgE and streptavidin-conjugated horseradish peroxidase (SAv-HRP) were added to the plates and plates were incubated for $1 \mathrm{~h}$ at $20^{\circ} \mathrm{C}$. Finally, tetramethylbenzidine (TMB) substrate solution was added to the plates and after 15 min incubation in the dark, $2 \mathrm{~N} \mathrm{H}_{2} \mathrm{SO}_{4}$ solution was added to stop the reaction. Optical densities were measured at 
A

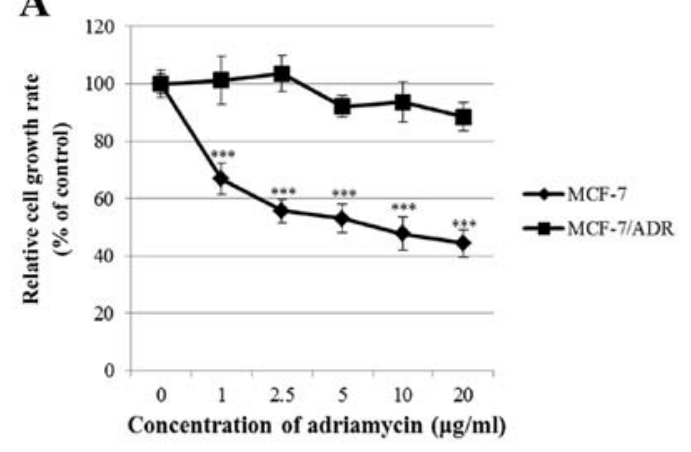

B

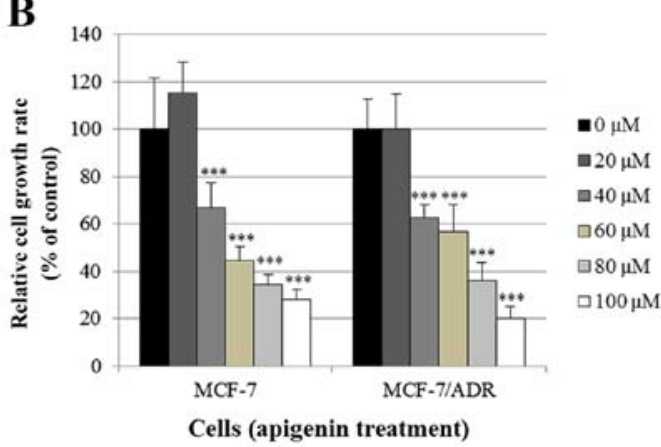

C

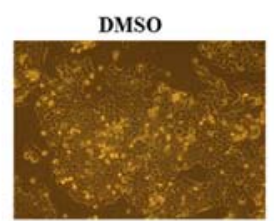

Apigenin $(40 \mu \mathrm{M})$
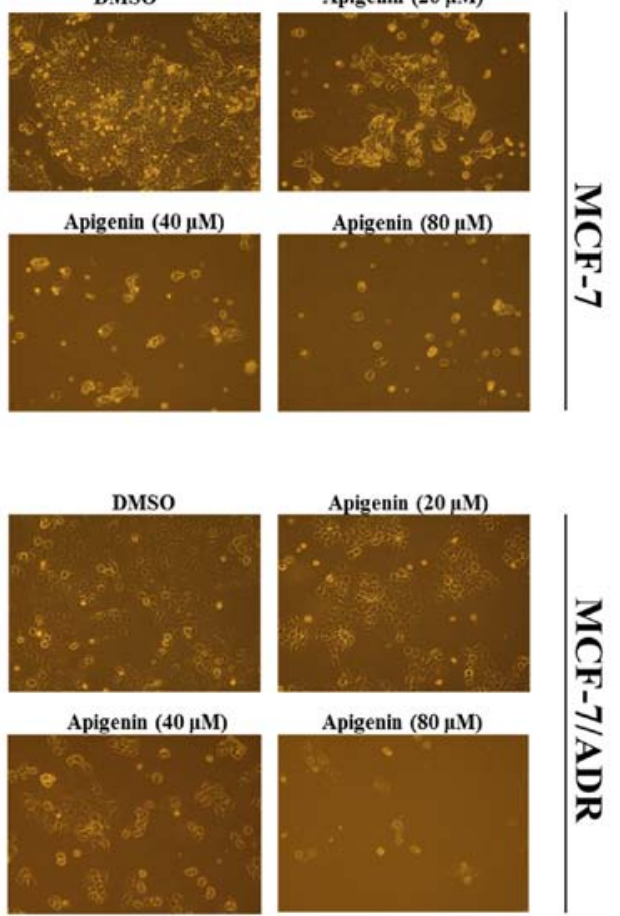

Figure 1. Apigenin suppresses the growth of MCF-7/ADR cells. (A) MCF-7 and MCF-7/ADR cells were treated with various doses of adriamycin (0-20 $\mu \mathrm{g} / \mathrm{ml})$. After $48 \mathrm{~h}$, the relative cell growth rate was assessed by MTT assay. (B) MCF-7 and MCF-7/ADR cells were treated with different various doses of apigenin $(0-100 \mu \mathrm{M})$. After $72 \mathrm{~h}$, the relative cell growth rate was assessed by MTT assay. (C) MCF-7 and MCF-7/ADR cells were treated with various doses of apigenin for $72 \mathrm{~h}$ and photographed by phase-contrast microscopy (original magnification, $\mathrm{x} 40$ ). The data are shown as the means of three independent experiments (error bars denote SD). ${ }^{*} \mathrm{p}<0.05,{ }^{* *} \mathrm{p}<0.01,{ }^{* * *} \mathrm{p}<0.001$
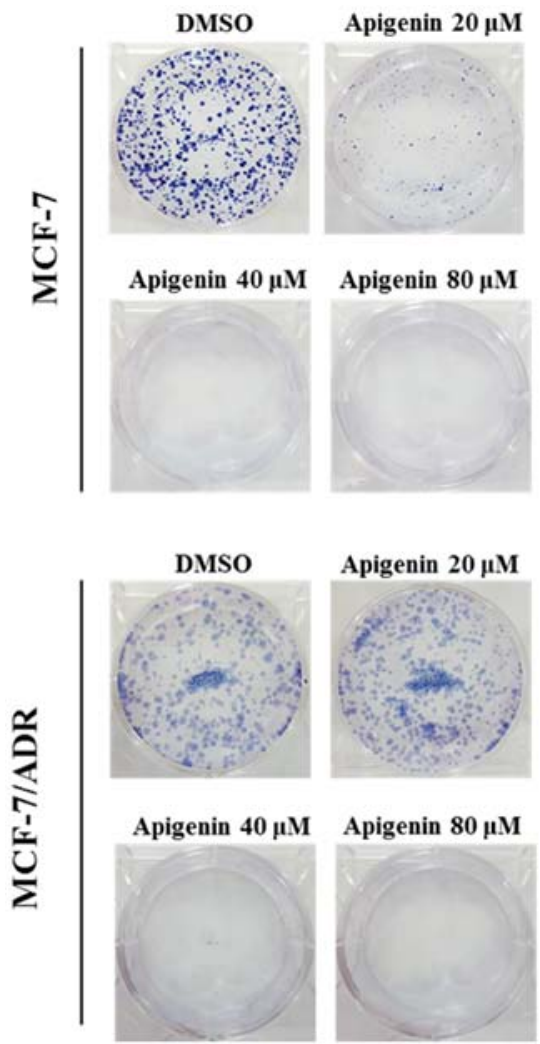
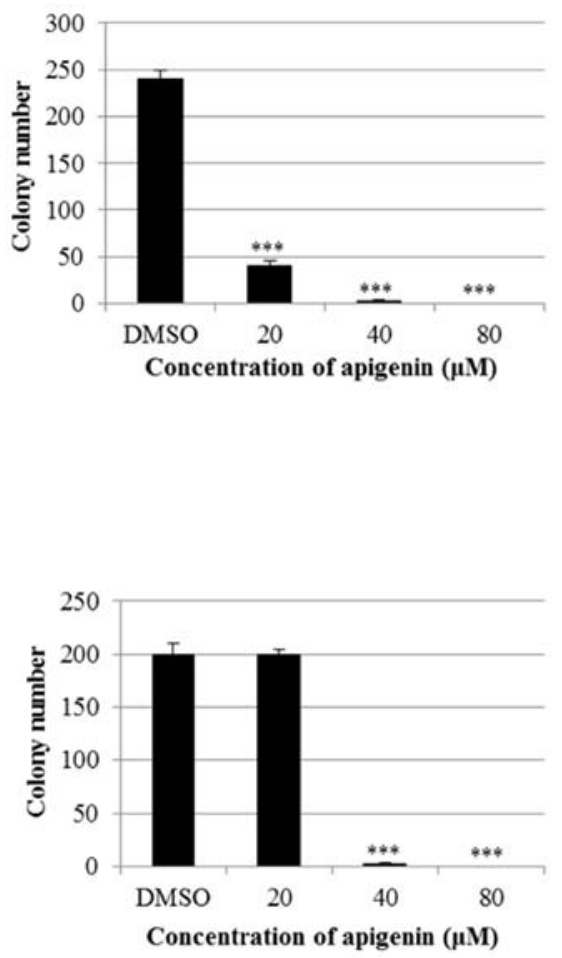

Figure 2. Apigenin inhibits the clonogenic survival of MCF-7/ADR cells. MCF-7 and MCF-7/ADR cells were plated in 6-well culture plates at a density of $5 \times 10^{2}$ cells/well. After overnight incubation, the cells were treated with various concentrations of apigenin $(0-80 \mu \mathrm{M})$ and maintained for 10 days at $37^{\circ} \mathrm{C}$. Finally, the plates were stained with hematoxylin, and the colony numbers were counted. The data shown are representative of three independent experiments that gave similar results. 
A
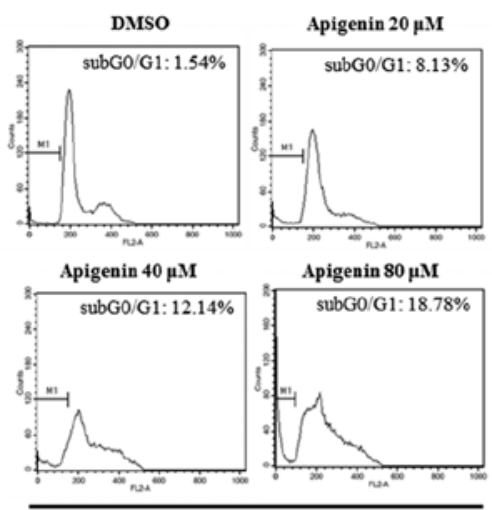

MCF-7

\section{B}

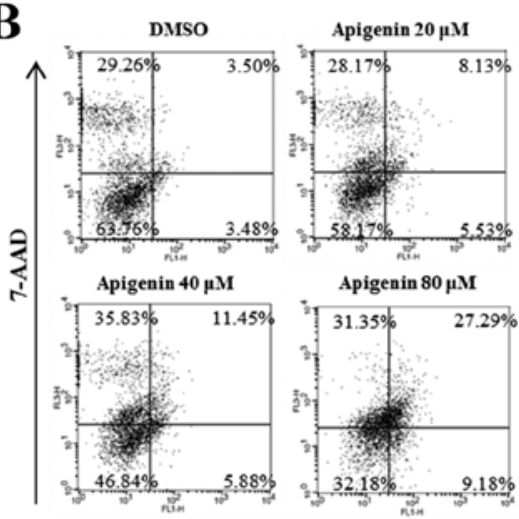

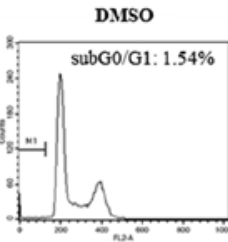

Apigenin $40 \mu \mathrm{M}$

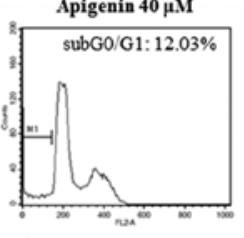

Apigenin $20 \mu \mathrm{M}$

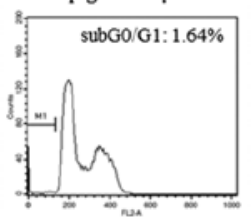

Apigenin $80 \mu \mathrm{M}$

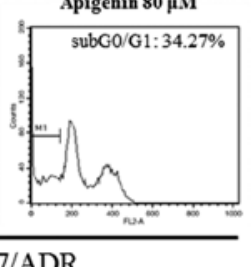

MCF-7/ADR
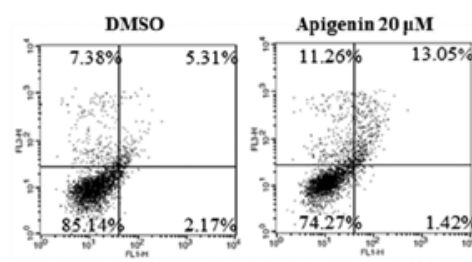

Apigenin $80 \mu \mathrm{M}$

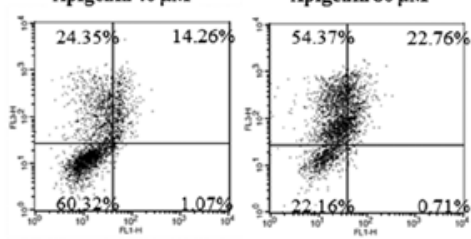

$22.76 \%$

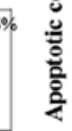

\section{产 0}

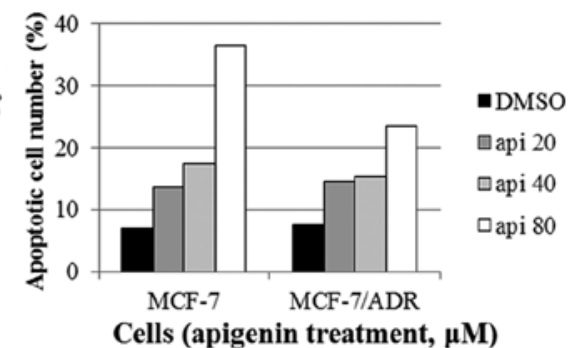

Annexin

MCF-7

MCF-7/ADR

C

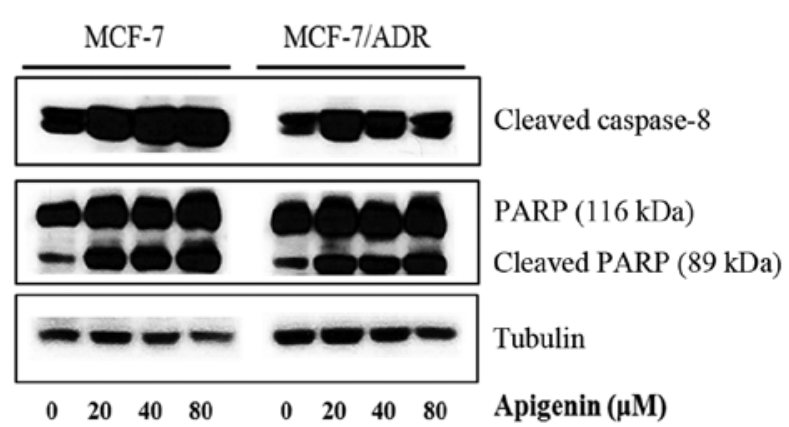

Figure 3. Apigenin induces apoptosis in MCF-7/ADR cells. (A) MCF-7 and MCF-7/ADR cells were treated with apigenin (0-80 $\mu \mathrm{M})$ and fixed $72 \mathrm{~h}$ later for flow cytometry. Propidium iodide-labeled nuclei were analyzed for DNA content. The sub- $\mathrm{G}_{0} / \mathrm{G}_{1}$ apoptotic population was quantified. (B) MCF-7 and MCF-7/ ADR cells were treated with apigenin $(0-80 \mu \mathrm{M})$ and harvested after $72 \mathrm{~h}$. Cells were stained with 7-AAD and Annexin V-FITC. Apoptotic cell death was analyzed with a BD FACSCalibur flow cytometer using the FL1 and FL3 channels. (C) MCF-7 and MCF-7/ADR cells were treated with apigenin (0-80 $\mu$ M) for $24 \mathrm{~h}$. Whole cell lysates were submitted to western blotting with anti-cleaved caspase-8, anti-PARP and anti-tubulin antibodies. The data shown are representative of three independent experiments that gave similar results.

$450 \mathrm{~nm}$ on an automated ELISA reader (Versa Max, Molecular Devices, Sunnyvale, CA, USA).

Rhodamine 123 efflux assay. MCF-7 and MCF-7/ADR cells were treated with apigenin $(0-80 \mu \mathrm{M})$ or nicardipine (positive control, $12.5 \mu \mathrm{M}$ ) for $24 \mathrm{~h}$ and incubated for another $1 \mathrm{~h}$ with $1 \mu \mathrm{g} / \mathrm{ml}$ of rhodamine 123 . Accumulation of rhodamine 123 in the cells was analyzed by flow cytometry.

Statistical analysis. All experiment results were expressed as the means \pm standard deviations (SD) of at least three separate tests. Student's t-test was used for single variable comparisons, and a P-value $<0.05$ was considered statistically significant. Statistical analyses were performed using PRISM software (GraphPad Software Inc., La Jolla, CA, USA).

\section{Results}

Apigenin suppresses the growth of MCF-7/ADR cells. Before investigating the effect of apigenin on the growth of adriamycin-resistant cells, we determined whether MCF-7/ADR cells display resistance to adriamycin. Fig. 1A demonstrates 

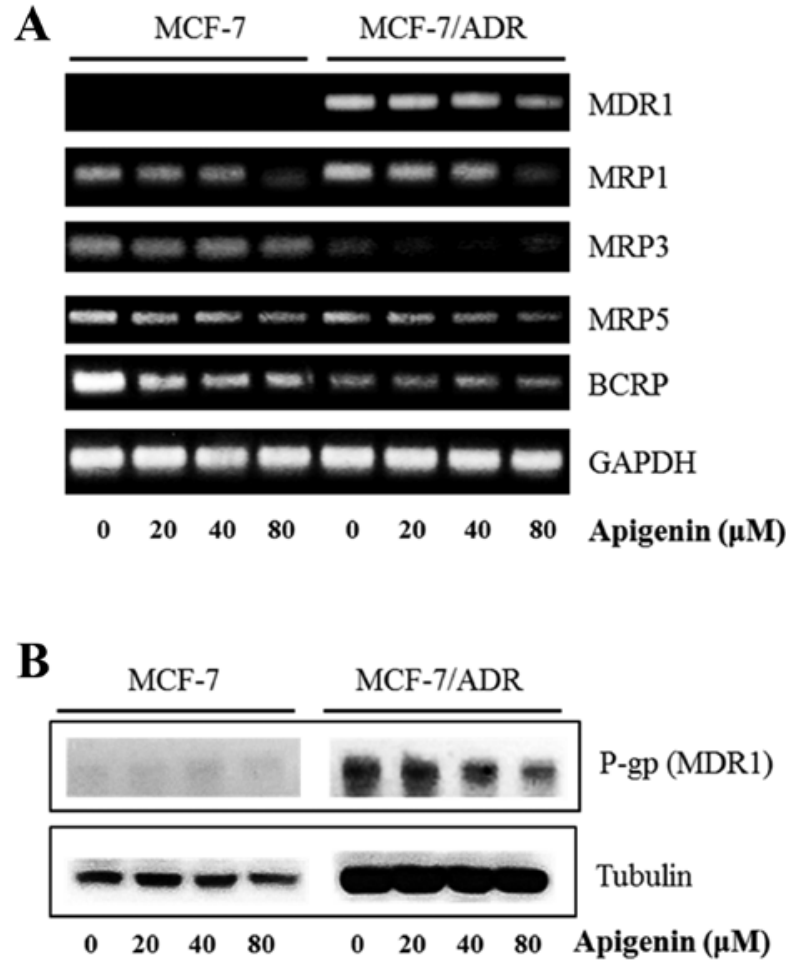

Figure 4. Apigenin downregulates MDR1 expression in MCF-7/ADR cells. (A) MCF-7 and MCF-7/ADR cells were treated with apigenin $(0-80 \mu \mathrm{M})$ for $24 \mathrm{~h}$, and the mRNA levels of MDR1, MRPs and BCRP were measured by RT-PCR. The data shown are representative of three independent experiments that gave similar results. (B) MCF-7 and MCF-7/ADR cells were treated with apigenin $(0-80 \mu \mathrm{M})$ for $24 \mathrm{~h}$. Whole cell lysates were submitted to western blotting with anti-MDR1 and anti-tubulin antibodies. The data shown are representative of three independent experiments that gave similar results.

that adriamycin decreased the growth rate of MCF-7 cells, while it did not affect the growth rate of MCF-7/ADR cells, confirming that the MCF-7/ADR cell line is adriamycin-resistant. Fig. 1B indicates that apigenin significantly suppressed the proliferation of both MCF-7 and MCF-7/ADR cells in a dose-dependent manner after $72 \mathrm{~h}$ of treatment. This growth inhibition induced by apigenin was confirmed by microscopic observation (Fig. 1C). Apigenin also induced morphological changes in these cells; the shape of the cells became round and shrunken. The changes were common both to MCF-7 and MCF-7/ADR (Fig. 1C). These results indicate that apigenin suppresses the growth of adriamycin-resistant cells.

Apigenin inhibits clonogenic survival of MCF-7/ADR cells. Next, we investigated the effect of apigenin on the clonogenic survival of MCF-7/ADR cells using a colony formation assay. As shown in Fig. 2, apigenin strongly inhibited colony formation in both MCF-7 and MCF-7/ADR cells in a dose-dependent manner. The effect of apigenin was stronger in MCF-7 cells than in MCF-7/ADR cells, as evidenced by the relative absence of colony formation in MCF-7 cells and the presence of colonies in MCF-7/ADR cells with $20 \mu \mathrm{M}$ treatment. These results indicate that MCF-7/ADR cells are drug-resistant and that apigenin overcomes this resistance.

Apigenin induces apoptosis in MCF-7/ADR cells. To study whether apigenin blocks cell proliferation by promoting changes in cell cycle progression, the effect of apigenin on the cell cycle profile was assessed in MCF-7 and MCF-7/ADR cells. For this purpose, cells were treated with apigenin $(0-80 \mu \mathrm{M})$ for $72 \mathrm{~h}$ and then analyzed for cell cycle stage by flow cytometry. The results demonstrated that apigenin induced an increase in the sub- $\mathrm{G}_{0} / \mathrm{G}_{1}$ apoptotic population in both cells (Fig. 3A). In the Annexin $\mathrm{V}$ assays, we found that apigenin increased the number of apoptotic cells in both cell lines (Fig. 3B). Moreover, we observed that apigenin induces not only apoptosis but necrosis. Consistent with these results, we also found that apigenin altered the apoptotic protein machineries; apigenin upregulated the levels of cleaved caspase- 8 and PARP in both cell lines (Fig. 3C). Therefore, our data indicate that apigenin induces apoptosis in chemotherapy-resistant breast cancer cells.

Apigenin downregulates MDR1 expression in MCF-7/ADR cells. Because P-gp (MDR1), multidrug resistance-associated proteins (MRP), and breast cancer resistance protein (BCRP), are important contributors to drug resistance, we checked whether apigenin regulates their expression. RT-PCR demonstrated that apigenin reduced the mRNA expression of MDR1, MRP1, MRP3, MRP5 and BCRP (Fig. 4). Western blot analysis indicated that P-gp (MDR1) was not induced in MCF-7 cells in the presence or absence of apigenin, while apigenin decreased the protein expression of P-gp (MDR1) at $80 \mu \mathrm{M}$ in MCF-7/ADR cells (Fig. 4). These results indicate that apigenin inhibits drug resistance by reducing the expression of drug resistance proteins in MCF-7/ADR cells.

Apigenin recovers accumulation of rhodamine 123 in MCF-7/ $A D R$ cells. Because drug resistance is associated with drug efflux by the cells, we performed a rhodamine 123 assay to investigate whether apigenin recovers drug accumulation in MCF-7/ADR cells. As expected, rhodamine 123 accumulation was high in the MCF-7 cell line, which is a drug-sensitive cell line (Fig. 5). In contrast, rhodamine 123 was ejected from the drug-resistant MCF-7/ADR cells, but apigenin recovered rhodamine 123 accumulation (Fig. 5). These results indicate that apigenin inhibits drug resistance by suppressing drug efflux in MCF-7/ADR cells.

Apigenin inhibits the STAT3 signaling pathway, resulting in suppression of drug resistance. Since STAT3 is related to oncogenic signaling, and it is known that STAT3 deactivation reverses chemotherapeutic resistance (27), we investigated whether apigenin inhibits the STAT3 signaling pathway in MCF-7/ADR cells. We found that apigenin reduced the expression of p-STAT3 in both MCF-7 and MCF-7/ADR cells (Fig. 6A). Immunocytochemical study demonstrated that apigenin decreased the nuclear localization of STAT3 in both MCF-7 and MCF-7/ADR cells (Fig. 6B). ELISA demonstrated that apigenin decreased the production of intracellular VEGF and MMP-9, which are STAT3 target genes in both MCF-7 and MCF-7/ADR cells (Fig. 6C and D). Moreover, the STAT3 inhibitor S3I-201, the JAK inhibitor I, and the HIF-1 $\alpha$ inhibitor EF-24 induced cell growth inhibition in both MCF-7 and MCF-7/ADR cells, as shown in Fig. 7A-C. Fig. 7D demonstrates that both apigenin $(80 \mu \mathrm{M})$ and the STAT3 inhibitor S3I-201 reduced the expression of p-STAT3, P-gp (MDR1) 
MCF-7
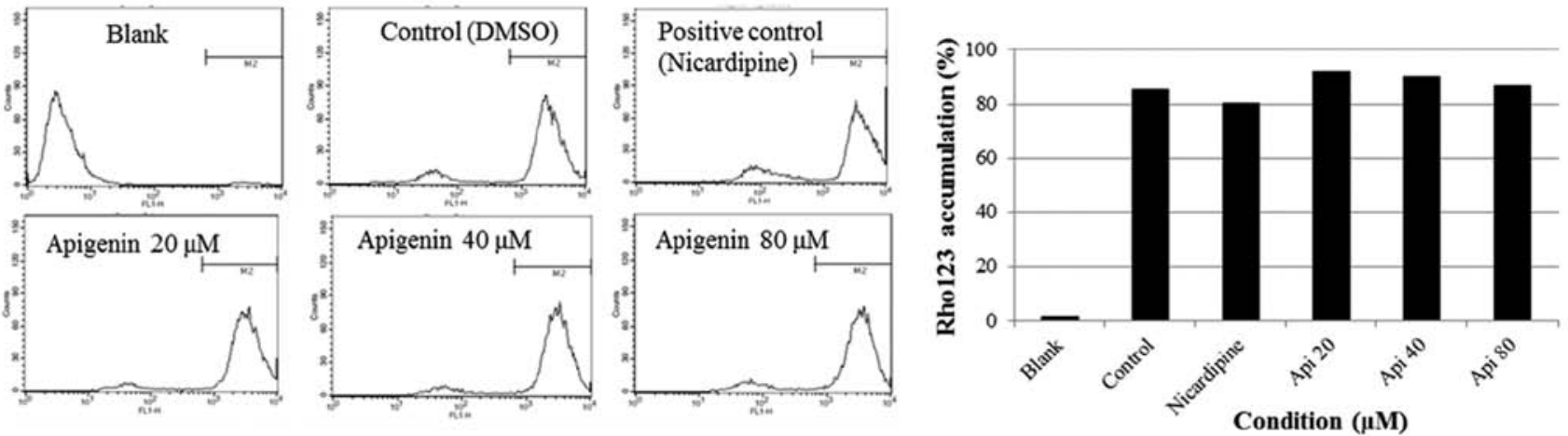

\section{MCF-7/ADR}
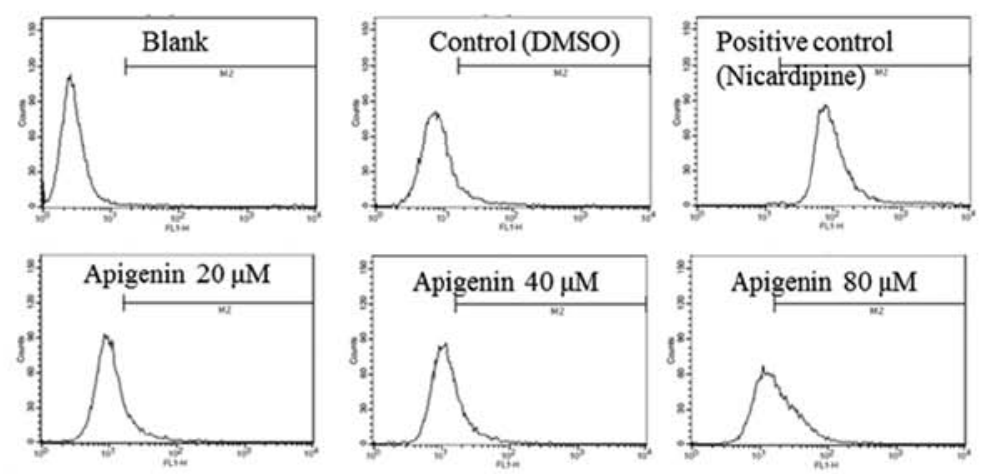

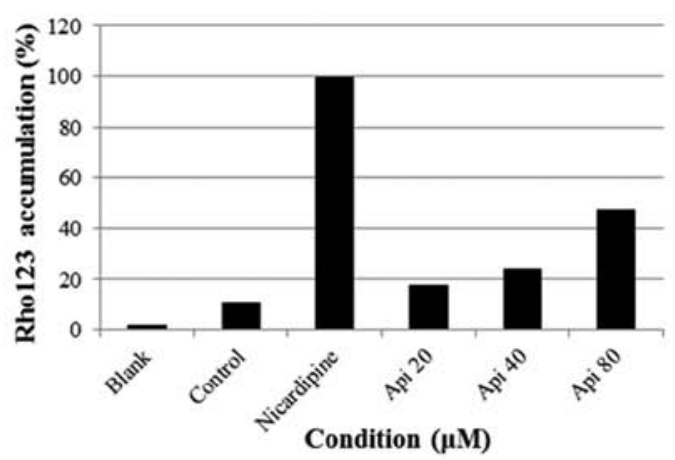

Figure 5. Apigenin recovers the accumulation of rhodamine 123 in MCF-7/ADR cells. MCF-7 and MCF-7/ADR cells were treated with apigenin (0-80 $\mu \mathrm{M})$ or nicardipine (positive control, $12.5 \mu \mathrm{M}$ ) for $24 \mathrm{~h}$ and incubated for another $1 \mathrm{~h}$ with rhodamine 123 . Rhodamine 123 accumulation was analyzed by flow cytometry.

A

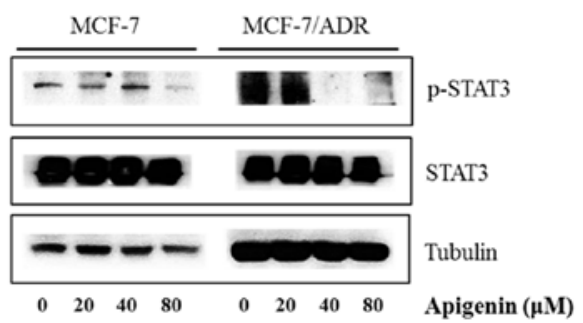

B

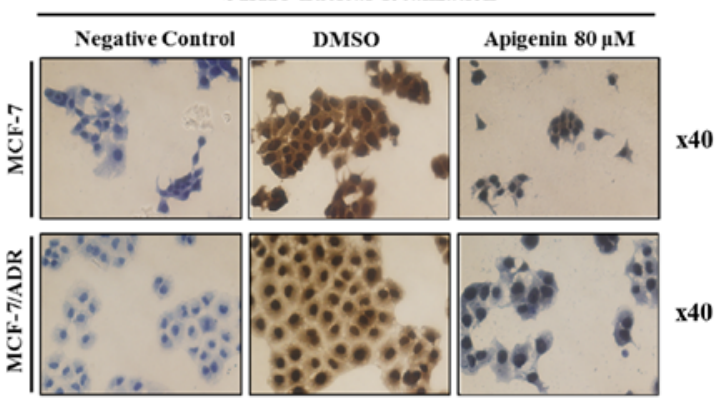

C

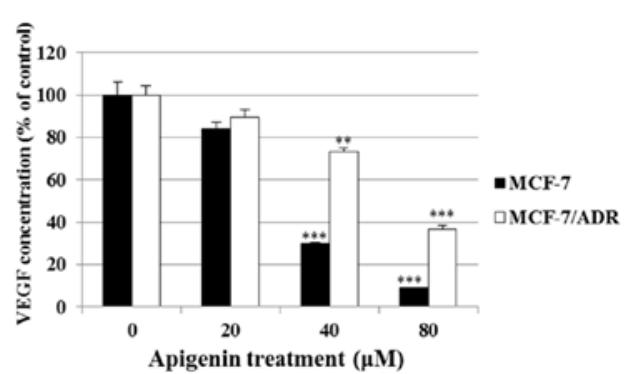

D

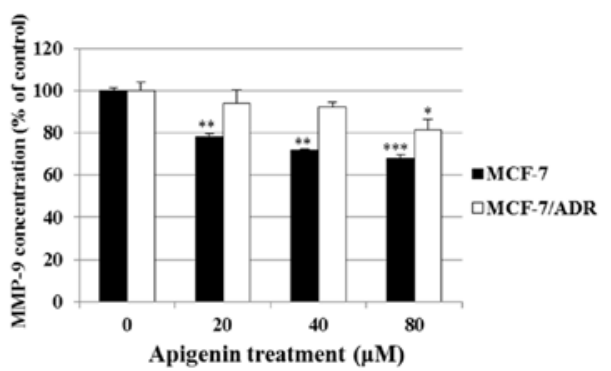

Figure 6. Apigenin inhibits the STAT3 signaling pathway. (A) MCF-7 and MCF-7/ADR cells were treated with apigenin ( $0-80 \mu \mathrm{M})$ for $24 \mathrm{~h}$. Whole cell lysates were submitted to western blotting with anti-p-STAT3, anti-STAT3 and anti-tubulin antibodies. The data shown are representative of three independent experiments that gave similar results. (B) MCF-7 and MCF-7/ADR cells were treated with apigenin $(80 \mu \mathrm{M})$ for $24 \mathrm{~h}$ and submitted to immunocytochemistry for detection of nuclear STAT3. The data shown are representative of three independent experiments that gave similar results. (C and D) MCF-7 and MCF-7/ ADR cells were treated with apigenin $(0-80 \mu \mathrm{M})$ for $24 \mathrm{~h}$, and the intracellular VEGF and MMP-9 concentration was measured by ELISA. The data are shown as the means of three independent experiments (error bars denote SD). ${ }^{*} \mathrm{p}<0.05,{ }^{* *} \mathrm{p}<0.01,{ }^{* * * *} \mathrm{p}<0.001$. 

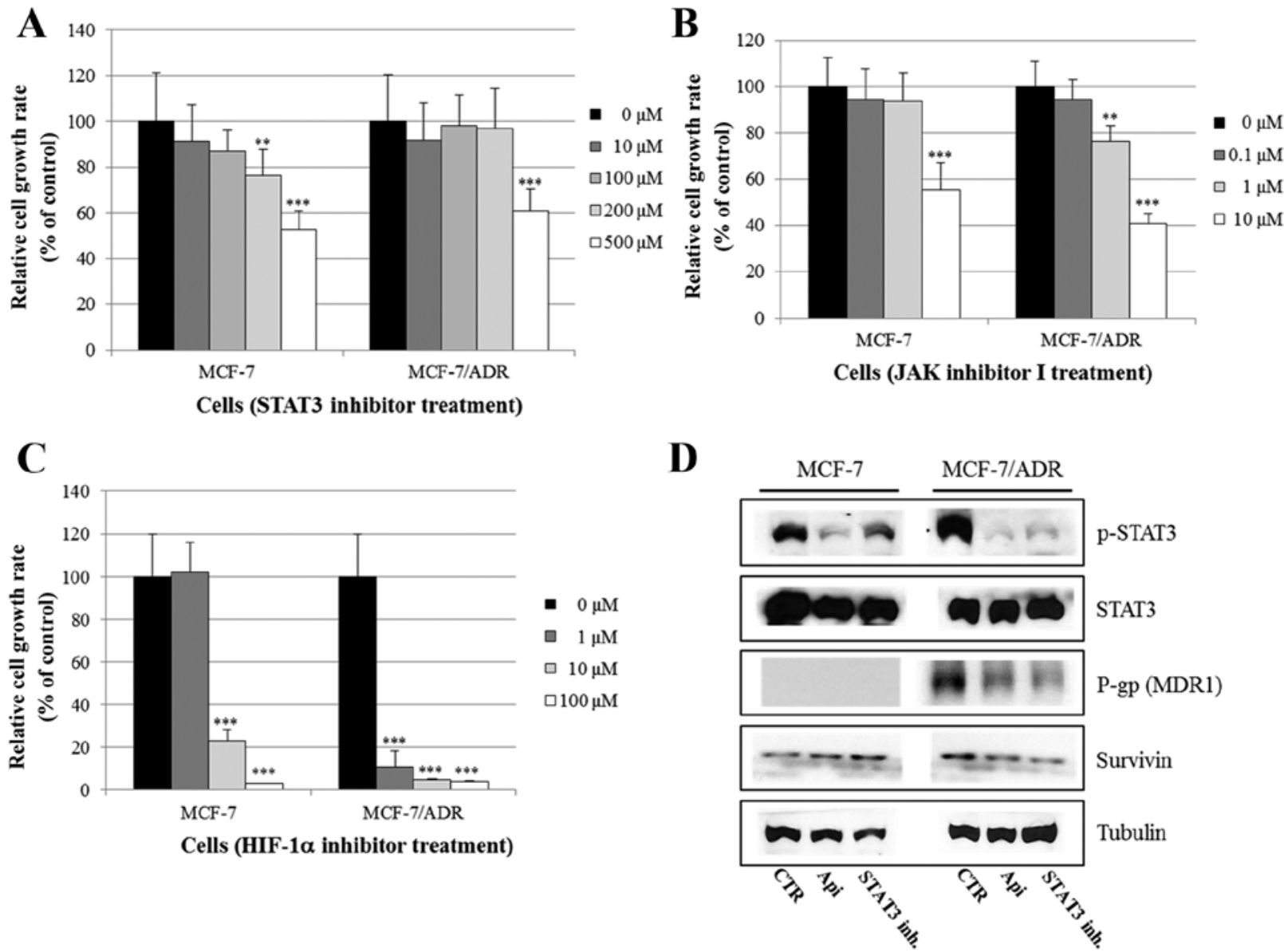

Figure 7. Inhibition of STAT3 signaling induces the growth suppression of MCF-7/ADR cells. (A-C) MCF-7 and MCF-7/ADR cells were treated with a STAT3 inhibitor (S3I-201, 0-500 $\mu \mathrm{M})$, JAK inhibitor I $(0-10 \mu \mathrm{M})$ and a HIF-1 $\alpha$ inhibitor (EF-24, 0-100 $\mu \mathrm{M})$ for $72 \mathrm{~h}$. The relative cell growth rate was measured by MTT assay. The data are shown as the means of three independent experiments (error bars denote SD). ${ }^{*} \mathrm{p}<0.05,{ }^{* *} \mathrm{p}<0.01,{ }^{* * *} \mathrm{p}<0.001$. (D) MCF-7 and MCF-7/ ADR cells were treated with apigenin $(80 \mu \mathrm{M})$ and a STAT3 inhibitor (S3I-201, $500 \mu \mathrm{M})$ for $24 \mathrm{~h}$. Whole cell lysates were submitted to western blotting with anti-p-STAT3, anti-STAT3, anti-MDR1, anti-survivin and anti-tubulin antibodies. The data shown are representative of three independent experiments that gave similar results.

and survivin (a STAT3 target gene) in MCF-7/ADR cells. These results indicate that apigenin suppresses drug resistance by inhibiting the STAT3 signaling pathway in MCF-7/ADR cells. Therefore, STAT3 may be a promising therapeutic target for overcoming drug resistance in breast cancer.

\section{Discussion}

Multidrug resistance (MDR) is a serious problem that leads to therapeutic failure in various cancers, and overcoming MDR is an important endeavor that is necessary to increase the overall survival of cancer patients. Natural plant products, such as phytoestrogens, are objects of intense research for their potential to reverse MDR, which would result in successful chemotherapy treatments. In the present study, the mechanism by which apigenin overcomes drug resistance was investigated in breast cancer. The aim of the study was to determine whether apigenin might be a useful compound for reversing drug resistance. For this purpose, we used the adriamycin-resistant MCF-7/ADR cells.

Apigenin significantly inhibited the growth of both MCF-7 and MCF-7/ADR cells. The clonogenic survival assay revealed that apigenin decreased anchorage-dependent colony formation of both cell lines in a dose-dependent manner. This growth inhibition was associated with an increase in the sub- $\mathrm{G}_{0} / \mathrm{G}_{1}$ apoptotic population in MCF-7 and MCF-7/ADR cells. Apigenin increased the number of apoptotic cells in a dose-dependent manner, as assessed by Annexin V assays. Moreover, apigenin induced apoptosis via a caspase-dependent apoptosis pathway, as shown by the cleavage of caspase- 8 and PARP. We did not detect caspase-3, which is important in the apoptosis pathway, because MCF-7 cells do not contain caspase-3 due to a genomic deletion (28). Our results indicate that apigenin contains strong apoptotic properties. Activation of apoptotic caspases induces inactivation or activation of substrates, leading to a signaling cascade, and the initiation of this signaling pathway permits the controlled destruction of cellular components (29). Apigenin-induced apoptosis seems to be mediated by the activation of caspase- 8 .

Apigenin downregulated the mRNA expression of MDR1 and MRPs, as well as the protein expression of P-gp (MDR1). Apigenin also inhibited drug efflux from the MCF-7/ADR adriamycin-resistant cells in a dose-dependent manner, as revealed by the rhodamine 123 efflux assay. These results indicate that apigenin overcomes drug resistance. In agreement with our data, it was reported that apigenin inhibits 
anti-estrogen-resistant breast cancer cell growth through estrogen receptor- $\alpha$-dependent and independent mechanisms (30). It was also reported that apigenin inhibited not only P-gp (MDR1) but also BCRP by increasing cellular uptake of adriamycin in multidrug-resistant cells (31). P-gp is a transmembrane glycoprotein that diminishes intracellular drug concentrations by pumping drugs out of the cells (27). Regulation of P-gp expression is important to avoid drug resistance; overexpression of $\mathrm{P}-\mathrm{gp}$ induces resistance to chemotherapeutic reagents. Apigenin appears to inhibit $\mathrm{P}$-gp-mediated drug resistance in MCF-7/ADR cells.

Interestingly, apigenin reduced the expression of p-STAT3, suggesting that it negatively regulates the STAT3 pathway in MCF-7/ADR cells. Apigenin inhibited nuclear localization of STAT3 in MCF-7/ADR cells, as revealed by immunocytochemistry. Apigenin inhibited the production of VEGF and MMP-9, which are STAT3 target genes, in MCF-7/ADR cells, as revealed by the ELISA assay. The STAT3 inhibitor S3I-201, JAK inhibitor I and the HIF-1 $\alpha$ inhibitor EF-24 decreased the growth of both MCF-7 and MCF-7/ADR cells. These results clearly indicate that apigenin induces growth-suppressive activity and overcomes drug resistance by inhibiting the STAT3 signaling pathway. STAT3 is a transcription factor that regulates target gene expression in response to cytokines or growth factors and plays a key role in many cellular processes. STAT3 traditionally operates as a cancer promoter, however, it upregulates cancer suppressor genes as revealed recently $(32,33)$. STAT3 promotes the increase of cell growth, angiogenesis, invasion and metastasis and inhibits apoptosis (34-36). Overexpression of STAT3 and p-STAT3 is related to poor prognosis in melanoma cancer (34-36). Several upstream kinases (Jak and Src) are responsible for the constitutive STAT3 phosphorylation $(37,38)$. It is known that resveratrol inhibits STAT3 signaling inducing cancer cells containing p-STAT3 (39). STAT3 (40) and HIF-1 (41) can bind to VEGF promoter which contains various transcription factor binding sites. The interaction of STAT3 with HIF-1 induces VEGF transcriptional activation (42). Constitutive activation of STAT3 is responsible for the resistance to chemotherapy-induced apoptosis in some tumors (27). Moreover, it was reported that multidrug resistance was associated with STAT3 mRNA overexpression in cisplatin-resistant lung cancer cells (27). STAT3 is activated highly in MDR malignancies, and inhibition of STAT3 activity might reverse chemoresistance (27). Constitutive activation of the STAT3 pathway could be an early indicator of drug resistance. Therefore, apigenin seems to reverse drug resistance by inhibiting STAT3 signaling, which indicates that apigenin could be a useful natural therapy that overcomes drug resistance.

It should be noted that apigenin acts as a suppressor of MUC1 expression in MCF-7 brest cancer cells. Moreover, it was proved that this loss of expression is associated with the loss of viability of MCF-7 cells (43). Apigenin could be a promising therapy for the treatment and prevention of breast cancer.

\section{Acknowledgements}

This study was supported by the Basic Science Research Program through the National Research Foundation of
Korea (NRF), funded by the Ministry of Science, ICT and Future Planning (2015R1C1A2A01051539). This study was also supported by a grant funded by the Traditional Korean Medicine R\&D Project of the Ministry of Health and Welfare (HI12C1889 and HI13C0530).

\section{References}

1. Holohan C, Van Schaeybroeck S, Longley DB and Johnston PG: Cancer drug resistance: An evolving paradigm. Nat Rev Cancer 13: 714-726, 2013.

2. Luqmani YA: Mechanisms of drug resistance in cancer chemotherapy. Med Princ Pract 14 (Suppl 1): 35-48, 2005.

3. Zahreddine $\mathrm{H}$ and Borden KL: Mechanisms and insights into drug resistance in cancer. Front Pharmacol 4: 28, 2013.

4. Xue X and Liang XJ: Overcoming drug efflux-based multidrug resistance in cancer with nanotechnology. Chin J Cancer 31: 100-109, 2012.

5. Amin ML: P-glycoprotein inhibition for optimal drug delivery. Drug Target Insights 7: 27-34, 2013.

6. Lee JH, Zhou HY, Cho SY, Kim YS, Lee YS and Jeong CS: Anti-inflammatory mechanisms of apigenin: inhibition of cyclooxygenase- 2 expression, adhesion of monocytes to human umbilical vein endothelial cells, and expression of cellular adhesion molecules. Arch Pharm Res 30: 1318-1327, 2007.

7. Romanová $\mathrm{D}$, Vachálková $\mathrm{A}$, Cipák L, Ovesná $\mathrm{Z}$ and Rauko $\mathrm{P}$ : Study of antioxidant effect of apigenin, luteolin and quercetin by DNA protective method. Neoplasma 48: 104-107, 2001.

8. Moon DO, Kim MO, Choi YH, Lee HG, Kim ND and Kim GY: Gossypol suppresses telomerase activity in human leukemia cells via regulating hTERT. FEBS Lett 582: 3367-3373, 2008

9. Nakazawa T, Yasuda T, Ueda J and Ohsawa K: Antidepressant-like effects of apigenin and 2,4,5-trimethoxycinnamic acid from Perilla frutescens in the forced swimming test. Biol Pharm Bull 26: 474-480, 2003.

10. Shukla S and Gupta S: Apigenin: A promising molecule for cancer prevention. Pharm Res 27: 962-978, 2010.

11. Heederik D, Kromhout H, Burema J, Biersteker K and Kromhout D: Occupational exposure and 25-year incidence rate of non-specific lung disease: The Zutphen Study. Int J Epidemiol 19: 945-952, 1990.

12. Knekt P, Järvinen R, Seppänen R, Hellövaara M, Teppo L, Pukkala E and Aromaa A: Dietary flavonoids and the risk of lung cancer and other malignant neoplasms. Am J Epidemiol 146: 223-230, 1997.

13. Hertog MG, Feskens EJ, Hollman PC, Katan MB and Kromhout D: Dietary flavonoids and cancer risk in the Zutphen Elderly Study. Nutr Cancer 22: 175-184, 1994.

14. Rossi M, Negri E, Lagiou P, Talamini R, Dal Maso L, Montella M, Franceschi S and La Vecchia C: Flavonoids and ovarian cancer risk: A case-control study in Italy. Int J Cancer 123: 895-898, 2008.

15. Bosetti C, Spertini L, Parpinel M, Gnagnarella P, Lagiou P, Negri E, Franceschi S, Montella M, Peterson J, Dwyer J, et al: Flavonoids and breast cancer risk in Italy. Cancer Epidemiol Biomarkers Prev 14: 805-808, 2005.

16. Shukla S, Bhaskaran N, Babcook MA, Fu P, Maclennan GT and Gupta S: Apigenin inhibits prostate cancer progression in TRAMP mice via targeting PI3K/Akt/FoxO pathway. Carcinogenesis 35: 452-460, 2014.

17. Budhraja A, Gao N, Zhang Z, Son YO, Cheng S, Wang X, Ding S, Hitron A, Chen G, Luo J, et al: Apigenin induces apoptosis in human leukemia cells and exhibits anti-leukemic activity in vivo. Mol Cancer Ther 11: 132-142, 2012.

18. Liu LZ, Fang J, Zhou Q, Hu X, Shi X and Jiang BH: Apigenin inhibits expression of vascular endothelial growth factor and angiogenesis in human lung cancer cells: Implication of chemoprevention of lung cancer. Mol Pharmacol 68: 635-643, 2005.

19. Seo HS, Ju JH, Jang K and Shin I: Induction of apoptotic cell death by phytoestrogens by up-regulating the levels of phospho-p53 and p21 in normal and malignant estrogen receptor $\alpha$-negative breast cells. Nutr Res 31: 139-146, 2011.

20. Lu HF, Chie YJ, Yang MS, Lee CS, Fu JJ, Yang JS, Tan TW, Wu SH, Ma YS, Ip SW, et al: Apigenin induces caspase-dependent apoptosis in human lung cancer A549 cells through Bax- and Bcl-2-triggered mitochondrial pathway. Int J Oncol 36: $1477-1484,2010$. 
21. Wang W, Heideman L, Chung CS, Pelling JC, Koehler KJ and Birt DF: Cell-cycle arrest at $\mathrm{G} 2 / \mathrm{M}$ and growth inhibition by apigenin in human colon carcinoma cell lines. Mol Carcinog 28: $102-110,2000$

22. Turktekin M, Konac E, Onen HI, Alp E, Yilmaz A and Menevse S: Evaluation of the effects of the flavonoid apigenin on apoptotic pathway gene expression on the colon cancer cell line (HT29). J Med Food 14: 1107-1117, 2011.

23. Gupta S, Afaq F and Mukhtar H: Involvement of nuclear factor-kappa B, Bax and Bcl-2 in induction of cell cycle arrest and apoptosis by apigenin in human prostate carcinoma cells. Oncogene 21: 3727-3738, 2002.

24. Ruela-de-Sousa RR, Fuhler GM, Blom N, Ferreira CV, Aoyama H and Peppelenbosch MP: Cytotoxicity of apigenin on leukemia cell lines: Implications for prevention and therapy. Cell Death Dis 1: e19, 2010.

25. Ujiki MB, Ding XZ, Salabat MR, Bentrem DJ, Golkar L, Milam B, Talamonti MS, Bell RH Jr, Iwamura T and Adrian TE: Apigenin inhibits pancreatic cancer cell proliferation through G2/M cell cycle arrest. Mol Cancer 5: 76, 2006.

26. Siveen KS, Sikka S, Surana R, Dai X, Zhang J, Kumar AP, Tan BK, Sethi G and Bishayee A: Targeting the STAT3 signaling pathway in cancer: Role of synthetic and natural inhibitors. Biochim Biophys Acta 1845: 136-154, 2014.

27. Zhang X, Xiao W, Wang L, Tian Z and Zhang J: Deactivation of signal transducer and activator of transcription 3 reverses chemotherapeutics resistance of leukemia cells via down-regulating P-gp. PLoS One 6: e20965, 2011.

28. Jänicke RU: MCF-7 breast carcinoma cells do not express caspase-3. Breast Cancer Res Treat 117: 219-221, 2009.

29. McIlwain DR, Berger T and Mak TW: Caspase functions in cell death and disease. Cold Spring Harb Perspect Biol 5: a008656, 2013

30. Long X, Fan M, Bigsby RM and Nephew KP: Apigenin inhibits antiestrogen-resistant breast cancer cell growth through estrogen receptor-alpha-dependent and estrogen receptor-alpha-independent mechanisms. Mol Cancer Ther 7: 2096-2108, 2008.

31. Saeed M, Kadioglu O, Khalid H, Sugimoto Y and Efferth T: Activity of the dietary flavonoid, apigenin, against multidrug-resistant tumor cells as determined by pharmacogenomics and molecular docking. J Nutr Biochem 26: 44-56, 2015.

32. de la Iglesia N, Konopka G, Puram SV, Chan JA, Bachoo RM, You MJ, Levy DE, Depinho RA and Bonni A: Identification of a PTEN-regulated STAT3 brain tumor suppressor pathway. Genes Dev 22: 449-462, 2008.
33. Lewis HD, Winter A, Murphy TF, Tripathi S, Pandey VN and Barton BE: STAT3 inhibition in prostate and pancreatic cancer lines by STAT3 binding sequence oligonucleotides: Differential activity between 5' and 3' ends. Mol Cancer Ther 7: 1543-1550, 2008.

34. Kortylewski M, Jove R and Yu H: Targeting STAT3 affects melanoma on multiple fronts. Cancer Metastasis Rev 24: 315-327, 2005.

35. Niu G, Bowman T, Huang M, Shivers S, Reintgen D, Daud A Chang A, Kraker A, Jove R and Yu H: Roles of activated Src and Stat3 signaling in melanoma tumor cell growth. Oncogene 21: 7001-7010, 2002.

36. Xie TX, Huang FJ, Aldape KD, Kang SH, Liu M, Gershenwald JE, Xie K, Sawaya R and Huang S: Activation of stat3 in human melanoma promotes brain metastasis. Cancer Res 66: 3188-3196, 2006.

37. Sellers LA, Feniuk W, Humphrey PP and Lauder H: Activated $G$ protein-coupled receptor induces tyrosine phosphorylation of STAT3 and agonist-selective serine phosphorylation via sustained stimulation of mitogen-activated protein kinase. Resultant effects on cell proliferation. J Biol Chem 274: 16423-16430, 1999.

38. Zhang Y, Turkson J, Carter-Su C, Smithgall T, Levitzki A, Kraker A, Krolewski JJ, Medveczky P and Jove R: Activation of Stat 3 in v-Src-transformed fibroblasts requires cooperation of Jak1 kinase activity. J Biol Chem 275: 24935-24944, 2000.

39. Kotha A, Sekharam M, Cilenti L, Siddiquee K, Khaled A, Zervos AS, Carter B, Turkson J and Jove R: Resveratrol inhibits Src and Stat 3 signaling and induces the apoptosis of malignant cells containing activated Stat 3 protein. Mol Cancer Ther 5: 621-629, 2006

40. Niu G, Wright KL, Huang M, Song L, Haura E, Turkson J, Zhang S, Wang T, Sinibaldi D, Coppola D, et al: Constitutive Stat3 activity up-regulates VEGF expression and tumor angiogenesis. Oncogene 21: 2000-2008, 2002.

41. Forsythe JA, Jiang BH, Iyer NV, Agani F, Leung SW, Koos RD and Semenza GL: Activation of vascular endothelial growth factor gene transcription by hypoxia-inducible factor 1 . Mol Cell Biol 16: 4604-4613, 1996.

42. Jung JE, Lee HG, Cho IH, Chung DH, Yoon SH, Yang YM, Lee JW, Choi S, Park JW, Ye SK, et al: STAT3 is a potential modulator of HIF-1-mediated VEGF expression in human renal carcinoma cells. FASEB J 19: 1296-1298, 2005.

43. Zhou Y, Rajabi H and Kufe D: Mucin 1 C-terminal subunit oncoprotein is a target for small-molecule inhibitors. Mol Pharmacol 79: $886-893,2011$ 